\title{
LUHMANN "FORA DO LUGAR”? \\ Como a "condição periférica" da América Latina impulsionou deslocamentos na teoria dos sistemas*
}

\section{Pedro Henrique Ribeiro}

\section{Introdução: Sociedade mundial e seus "lugares"}

Já disse Roberto Schwarz que "[a]o longo de sua reprodução social, incansavelmente o Brasil põe e repõe ideias europeias, sempre em sentido impróprio" (Schwarz, 2005, p. 29), que, "[s]ubmetidas à influência do lugar, sem perderem as pretensões de origem, gravitavam segundo uma regra nova, cujas graças, desgraças, ambiguidades e ilusões eram também singulares. Conhecer o Brasil era saber des-

* Em agradecimento ao professor Marcelo Neves e aos professores Orlando Villas Bôas-Filho, Frédéric Vandenberghe e Cynthia Hamlin. O professor Vandenberghe e a professora Hamlin presidiram, em 2011, a mesa do $35^{\circ}$ Encontro Anual da Anpocs, na qual a versão base desse artigo foi apresentada e discutida.

Artigo recebido em 30/03/2012

Aprovado em 08/05/2013 tes deslocamentos, vividos e praticados por todos como uma espécie de fatalidade, para os quais, entretanto, não havia nome, pois a utilização imprópria dos nomes era a sua natureza" (Idem, p. 26).

O reconhecimento de "ideias fora do lugar" "fora de centro, em relação ao seu uso europeu", e como algo constitutivo do "caráter nacional" brasileiro - recebeu diversas críticas por desconsiderar questôes vinculadas à estrutura social da "sociedade brasileira". ${ }^{1}$ Seja como for, a questão da especificidade do Brasil ou de outras regióes como a América Latina continua (ainda) a pautar discussões sociológicas contemporâneas, por vezes em contextos inesperados, como ocorre recentemente com a teoria luhmanniana.

As grandes "explicações do Brasil", principalmente pela influência dos ensaios sociológicos da década de 1930, preocuparam-se com as especificidades do país e se caracterizaram pela reapropriação de "temas e problemas" que levaram autores a 
"explorar determinadas perspectivas de leituras do passado" na busca pela identidade nacional (Lavalle, 2004, esp. pp. 69-70). Muitas dessas explicações foram caracterizadas por remeter a resquícios cristalizados do passado, em continuidades históricas que serviam como explicações abrangentes ou totalizantes. Nelas se destaca o caráter anômalo, pré-moderno e atrasado do Brasil, como evidenciam as análises do caráter nacional do ethos ibérico (Villas Bôas Filho, 2009, esp. pp. 187 e ss.) e do ethos público para explicar a falta de possibilidade de constituição de um espaço coletivo no país (Lavalle, 2004). O "pensamento político brasileiro" (Brandão, 2005) tinha uma agenda manifestamente política e normativa: fundar a nação brasileira moderna ou demonstrar seus entraves e indicar suas possibilidades de superação para sua modernização. $\mathrm{O}$ problema de fundo não era apenas a caracterização teórica (explicação) do Brasil, mas também a descrição politicamente orientada de uma nação visando o problema de enfrentar o atraso e inseri-la na modernidade. $^{2}$

No entanto, não obstante esse debate, para além da questão das ideias e dos projetos políticos ou desenvolvimentistas para o país e das posteriores teorias da modernização e do progresso (que hoje parecemos querer evitar), é possível extrair desse debate outro ponto, não apenas político, mas também epistemológico: existe uma tensão subjacente a todas estas explicações que pode ser pensada como a tensão estrangeiro/autêntico, geral/particular ou, ainda, explicação pela regra/explicação pela exceção. Essa parece ser uma constante não apenas do pensamento social brasileiro, mas de toda uma tradição do pensamento social periférico ao tematizar precisamente sua "condição periférica" na modernidade (ou no capitalismo) "global". ${ }^{3}$

Este tema seria constitutivo não apenas do pensamento político brasileiro, mas também da sociologia latino-americana. Mascareño e Chernilo (2009, pp. 85 e ss.) chamam a atenção para a busca por aquilo que faria a América Latina ser simultaneamente moderna (universal) $e$ latino-americana (particular). Ao analisar a tensão entre universalismo e particularismo, os autores discorrem sobre como a sociologia latino-americana lidou com a questão da modernidade de forma ambivalente, associando, por um lado, sua identidade às fronteiras nacionais e aos "ethos culturais imutáveis" e, por outro, adotando as teorias sociológicas mais abstratas e gerais, de diferentes conjunturas, criadas e pensadas para tempos e contextos sociais muito diversos. Segundo os autores, não se trata de afirmar uma total impossibilidade da sociologia latino-americana de levar em conta suas especificidades empíricas e as demandas de conhecimento "universalmente orientado do cânone sociológico”, mas antes de reconhecer que tanto uma posição que foque apenas os particularismos quanto uma posição abstrata a-histórica que não leve em conta contextos específicos são, ambas, inatingíveis.

No extremo, e forçando o argumento, teríamos dois polos igualmente problemáticos: um de descrição pontual com baixa capacidade de comparação, explicação e generalização; outro com uma aplicação descontextualizada de teorias realizadas em/para contextos sociais diferentes, o que implicaria desconsiderar a "realidade" do objeto que pretendem analisar. Essa tensão paradoxal que mobiliza teorias universalistas para explicar sua própria negação em contextos determinados (sua exceção particularista) parece ser um elemento de produtividade no pensamento social em/sobre contextos periféricos. A comparação das "ideias fora de lugar" gerou muita discussão sobre formas de se compreender a periferia da modernidade e sua identidade. Parece-me, contudo, que o outro lado da mesma discussão está subaproveitado: além de se concentrar apenas no entendimento da periferia, por si ou por comparação, cumpre também indagar sobre a consistência interna de teorias generalizantes que se julgam adequadas para descrever a sociedade moderna de maneira abrangente (ou seja, englobando seus centros $e$ periferias). A pergunta se transfere, então, do potencial explicativo em relação a contextos regionais para a consistência interna de uma teoria que se pretende macrossociológica ou "superteórica", como é o caso da teoria luhmanniana. De maneira simplista cabe somar ao debate uma pergunta contraintuitiva: em vez de focar os contextos de "inautenticidade", "excentricidade" ou "excepcionalidade" da(s) "modernidade(s)-desvio" per se, caberia perguntar se não é a teoria dita universal, ela sim, que está fora de lugar na sociedade moderna. 
Como se pretende demonstrar a seguir, essa é precisamente a questão e o "valor" da macroteoria social de Niklas Luhmann, que respondeu ativamente às críticas de que sua teoria sofreria de um "provincianismo empírico" (Neves, 1992, p. 9; 2004, p. 167) e seria, portanto, inadequada para explicar os lugares/regiōes da sociedade mundial, procedendo a adequaçóes e deslocamentos teóricos em seu arcabouço conceitual. Sem encarar âmbitos regionais como "exceçôes" ou "contextos exóticos" (Luhmann, 1992), Luhmann trouxe o debate de volta para a consistência interna da teoria, o que implicou o começo de uma "virada" em sua descrição da diferenciação funcional.

Com isso não se quer propor uma "teoria panaceia" e resolver o paradoxo mencionado com uma teoria que dê conta dos dois polos do debate, mas, antes, como sustenta Luhmann, seria o caso de tornar o paradoxo produtivo precisamente por ser impossível resolvê-lo. Formulando de maneira não rigorosa, não parece ser possível um momento final de síntese (ou suprassunção - Aufhebung ${ }^{4}$ ) que seja tanto individualizante (descoberta de singularidades) quanto universalizante (reconhecimento de propriedades comuns) nos debates sobre modernidade. Ao mesmo tempo, também não parece ser interessante do ponto de vista heurístico rejeitar qualquer possibilidade de comparação entre contextos sociais diversos da sociedade moderna, como se disso necessariamente resultassem valoraçôes do "núcleo da modernidade", 5 mesmo porque, nas palavras de Luhmann (1995b, p. XLV), "uma teoria deve tornar comparações possíveis".

Assim, ao demonstrar que o pensamento luhmanniano realizou um "movimento de revisão" da teoria da diferenciação funcional e reconheceu a não homogeneidade da sociedade mundial (Weltgesellschaft) no nível regional, este artigo apresenta argumentos para apontar que não apenas o reconhecimento da condição periférica foi essencial para desenvolvimentos tardios da teoria luhmanniana em geral, como também que tais mudanças abrem novas possibilidades de debates para estudos contemporâneos. Com isso, de forma secundária, se pretende implicitamente apresentar uma faceta da teoria social de Niklas Luhmann que parece ser mal compreendida por diversos críticos que afir- mam ser sua teoria necessariamente cínica e "sintomática de nossa época" (Domingues, 2011, p. 100); fixadora de valores liberais, da diferenciação funcional, ou do status quo; ${ }^{6}$ ou ainda demasiada e inutilmente hermética (Bobbio, 2007, p. 112). Luhmann pode ser considerado excêntrico por suas bases teóricas, mas parece incorreto aferir que sua teoria não dialoga com questôes clássicas da teoria sociológica (ver Ribeiro, 2012, pp. 33 e ss.). Aliás, essa "virada" luhmanniana no reconhecimento de "limites da teoria da diferenciação funcional" parece ter aproximado a teoria de Luhmann de debates atuais mais próximos de teorias críticas e teorias da desigualdade social. ${ }^{7}$

É possível argumentar que essa revisão conceitual - e a importância "do pensamento social periférico" em impulsioná-la - podem ser remetidas a dois momentos: 1) o ano de 1992, quando o autor buscou responder às críticas de Marcelo Neves à amplitude dada pela teoria luhmanniana ao conceito de diferenciação funcional; 2) a incorporação do autor da realidade "além de descrição" das favelas sul-americanas nos anos seguintes. ${ }^{8}$

Tal argumento apoia-se na constatação de que o prefácio (Zur Einführung) de Luhmann à obra de Neves (Luhmann, 1992) talvez seja ${ }^{9}$ o primeiro texto em que o autor enfrenta a questão dos limites da teoria da diferenciação funcional de forma central, ${ }^{10}$ passando a esboçar de forma embrionária teses sustentadas em obras posteriores (1993, pp. 580 e ss.; 1995a; 1995c; 1998; 2000, pp. 247 e ss.; e [1997] 2007, esp. pp. 490 e ss. e 639 e ss.): ${ }^{11}$

Isso [crítica de Neves] aponta para problemas que nem a teoria de classe de proveniência marxista ou pós-marxista nem o conceito usual de diferenciação funcional da sociedade sabem dar uma resposta. Essas teorias estão, por isso, refutadas? Mas como, se não mediante uma outra teoria? Talvez os fatos descritos já permitam perceber que outras diferenças se sobrepõem às teorias de nossa tradição, construídas de maneira demasiadamente simples. Talvez a realização da diferenciação funcional no nível da sociedade mundial, com alta dinâmica interna da economia, da ciência, dos meios de comunicação de massas e da política, não queira dizer, por muito 
tempo, que as correspondentes condiçōes possam realizar-se também no plano regional. E talvez já haja, entrementes, indícios de uma diferença pré-ordenada, primordial, que regule o acesso às vantagens da diferenciação funcional, a saber, a diferença de inclusão e exclusão [...]. Isso significaria que a sociedade no Brasil é integrada de maneira dupla, a saber, positivamente através da rede de favores, de gratidões, de relações patrão/cliente, da corrupção, e negativamente mediante a exclusão prática de muitos da participação em todos os sistemas funcionais, situação em que uma exclusão (falta de documento, de trabalho, de alimentação regular, de educação, de seguro de saúde, da segurança do corpo e da vida) que forçosamente traz consigo, cada vez mais, outras exclusões.

Espera-se que o trabalho de Marcelo Neves não seja lido como se fosse apenas um conjunto de informações sobre relações jurídicas exóticas em um país da modernidade periférica, mas antes também para estimular o pensamento sobre a sociedade na qual nós vivemos hoje (Luhmann, 1992, pp. 3-4, grifos meus).

Para isso, após esta introdução, o presente estudo irá expor brevemente a caracterização da sociedade moderna em termos de uma sociedade mundial baseada no primado da diferenciação funcional por Niklas Luhmann e demonstrar as alteraçôes que esses conceitos sofreram após a virada teórica do enfrentamento da condição periférica da sociedade mundial. Por fim, abordam-se críticas e vantagens da distinção centro/periferia da sociedade mundial para, postertiormente, abordar de forma mais livre e ensaística algumas possibilidades abertas pela temática em discussões atuais.

\section{A teoria conforme a tematização da periferia}

\section{Sociedade moderna complexa e diferenciada funcionalmente}

Luhmann pretende desenvolver uma "teoria universal" do social, mesmo que não seja exclusiva (Luhmann, 1995b, pp. xlvii e ss.). Assim, para tra- balhar a teoria sociológica "em crise" (1995b, p. xlv; $1996 b$, p. 27) e dar-lhe unidade em um nível elevado de abstração (1981, pp. 195-196), Luhmann desenvolve uma teoria complexa que visa a refletir a complexidade da sociedade moderna que ela busca descrever (1995b, pp. xlix-l). Sua teoria social parte, pois, de pressupostos epistemológicos da teoria geral dos sistemas ${ }^{12}$ para criar uma descrição da sociedade moderna como um sistema social autopoiético cujo elemento é a comunicação. A sociedade é o sistema social mais abrangente e conta com diversos sistemas sociais "parciais", também autopoiéticos, como religião, ciência, arte, direito, política, economia etc. (2007a, pp. 55 e ss.). Cada sistema é compreendido não como um objeto, mas como uma "forma de dois lados", ou seja, uma distinção sistema/ambiente (dentre muitos, 2007, pp. 40 e ss.).

O que é mais interessante para nossa discussão é que Luhmann apresenta uma "teoria da evolução" não ontológica e não linear da sociedade (sem direção ou finalidade). $\mathrm{O}$ autor descreve como processos de "variação, seleção e (re)estabilização" ocorrem na diferenciação da sociedade (2007a, pp. 335, 380 e ss.). Com o advento da modernidade, a sociedade torna-se supercomplexa e descentralizada (heterárquica e multicêntrica, isto é, sem nenhum sistema central), o que gera uma pressão seletiva (Selektionszwang) impulsionando a diferenciação por funçōes que geram sistemas funcionalmente diferenciados - os sistemas parciais (2007, p. 473).

Portanto, para Luhmann (1990, p. 31), a sociedade moderna torna-se "inacessível" em sua totalidade: "uma sociedade organizada em subsistemas não dispõe de nenhum órgão central. É uma sociedade sem vértice e sem centro". A integração de tal sociedade só pode ser realizada, então, por meio de seus sistemas sociais parciais. Disso decorre que a diferenciação funcional é a aquilo que caracteriza primariamente a sociedade moderna em contraposição de sociedades pré-modernas ou tradicionais que se diferenciavam primacialmente por outros princípios, como em sociedades segmentárias e estratificadas (2007, pp. 482 e ss.).

Tal compreensão do conceito de sociedade resulta no conceito de "sociedade mundial" (Weltgesellschaft) (Luhmann, 1975; 1997c; 2007, pp. 
108 e ss.), algo que seria de difícil concepção, pois enfrentaria quatro obstáculos epistemológicos que impediriam a compreensão "adequada" do conceito de sociedade: 1) a sociedade estaria constituída por homens concretos e por relações entre seres humanos; 2) a sociedade se estabeleceria por consenso desses seres humanos; 3) as sociedades seriam unidades regionais, territorialmente delimitadas; 4) que portanto as sociedades podem se observar do exterior como humanos ou territórios (2007, p. 12). Ora, é precisamente o terceiro obstáculo que impediria reconhecer, segundo o autor, que a sociedade moderna seria caracterizada por ser uma sociedade mundial, uma vez que as comunicações não mais respeitariam fronteiras territoriais.

Nota-se, por fim, que o caráter "complexo" ou hermético de sua teoria social policêntrica (e consequentemente policontextural) busca se adequar a uma sociedade concebida acentricamente. Portanto, sua teoria não é apenas uma estrita correspondência ponto a ponto entre conceito e realidade; ela desenvolve complexidade própria precisamente para fins heurísticos. Nesse processo, afirma Luhmann, "por um lado, uma referência à realidade precisa ser salvaguardada. Por outro, entretanto, a ciência, especialmente a sociologia, não deve permitir ser enganada [duped] pela realidade. Visto dessa forma, a abstração é uma necessidade epistemológica" (1995b, p. li). Portanto, sua teoria é marcadamente não linear e sem centro (2005, p. 14). Luhmann compara seu desenho a um labirinto, em detrimento de uma "estrada para o pôr do sol" (1995b, p. lii). ${ }^{13}$

O ganho de abstração da teoria luhmanniana já foi reconhecido por diversos comentadores críticos ou não. Contudo, vimos que Luhmann advertiu: "alguma referência à realidade precisa ser salvaguardada”. Essa é precisamente a entrada que teve a crítica de Marcelo Neves e de outros pensadores da condição periférica, a saber: forçar o pensamento luhmanniano a dar conta do reconhecimento de seu "provincianismo empírico" (Neves, 1992, 2004) e a mobilizar sua rede abstrata de conceitos para tematizar uma sociedade mundial assimétrica e não homogênea, na qual o princípio da diferenciação funcional não se espraiou sem conflitos e variações. Afinal, não basta reconhecer que "há luzes e sombras na paisagem da modernidade" (Brunkhorst, 2005, p. 113); é necessário explicar a constituição dessa paisagem e como as luzes se relacionam com as sombras.

\section{Modernidade periférica e "provincianismo empírico"}

Há cerca de vinte anos, Marcelo Neves fez uma análise crítica do conceito luhmanniano de positividade do direito e da consequente eficácia da Constituição, demonstrando os limites de seu uso no contexto da modernidade periférica. Intentou-se realizar uma "irritação" do modelo luhmanniano de diferenciação sistêmica como princípio característico da modernidade, apontando diferenças estruturais em seu desenvolvimento e aplicação na sociedade mundial (Neves, 1992, p. 9).

Segundo Neves, o "terceiro mundo" era tratado de maneira inadequada tanto por teorias europeias e norte-americanas, que o concebiam como um conjunto de sociedades tradicionais, quanto por teorias da modernização e da dependência, que utilizavam o esquema conceitual antes/depois na aplicação de uma política desenvolvimentista ou se baseavam centralmente apenas na estrutura do capitalismo. O autor identifica, então, duas dimensões sincrônicas da sociedade mundial, após ter ocorrido uma bifurcação entre centro e periferia da modernidade (Neves, 1992, pp. 72-75; 2004, p. 146). Essa bifurcação é relacionada com a profunda desigualdade econômica no desenvolvimento inter-regional, trazendo consequências significativas na reprodução de todos os sistemas sociais, principalmente no político e no jurídico (Neves, 1992, p. 75; 2006, pp. 226-227).

Sua análise da subintegração de regiōes na sociedade mundial parte de um caráter primariamente econômico (força do código da economia), o que o levou a reconhecer que a mundialização (expansão da sociedade mundial) era guiada por uma preferência por sistemas sociais baseados em expectativas cognitivas, dispostas ao aprendizado, como economia, ciência e técnica. Por outro lado, os sistemas jurídico e político, vinculados a expectativas normativas, teriam menor capacidade de expansão, contando com uma segunda diferenciação 
no plano dos territórios (Neves, 1992, p. 75). Aliás, essa já fora a posição de Luhmann (1975, p. 68), que posteriormente radicalizaria sua teoria da diferenciação horizontal (Neves, 2006, p. 218).

Com isso, a sociedade teria uma divisão dicotômica e hierárquica estruturada em centro e periferia (Neves, 1992, p. 75). Neves chama a atenção para fatores e especificidades locais e regionais que funcionariam como fatores de desenvolvimento, gerando níveis prestacionais diferentes no âmbito regional. Posteriormente, Neves atenta para o fato de que a teoria luhmanniana vincula a emergência da sociedade moderna em sua teoria da evolução a partir da noção de complexidade, tida como o elemento impulsionador da modernidade (em conformidade com Luhmann, 1983, pp. 45 e 172). Além de diferenciar conceitualmente os "tipos ideais" do centro e periferia da sociedade mundial apresentando a relação assimétrica entre eles, Neves caracteriza a modernidade periférica por lidar com a hipercomplexidade do ambiente de forma desestruturada ou desorganizada. Com isso, a autonomia autopoiética do direito e da política ficaria prejudicada, e o funcionamento desses subsistemas sociais e do Estado de Direito seria bloqueado generalizadamente em sua autoprodução por injunções heterônomas de outros códigos e critérios sistêmicos (Neves, 1992; 2006, pp. 239 e ss.). Após a desintegração moral da sociedade tradicional, não teriam surgido sistemas autopoiéticos autônomos, o que gerou, portanto, "complexidade desestruturada”. Daí porque, em sua primeira formulação, Neves concebia a modernidade periférica como "modernidade negativa" (1994, p. 264), conceito posteriormente abandonado.

Tal situação é trabalhada a partir da ideia de "corrupção sistêmica”. Nota-se que ele se refere ao bloqueio do funcionamento operativamente fechado de um sistema determinado, que em tese pode ser aplicado a qualquer subsistema social. Por isso, ainda que Neves reconheça a corrupção sistêmica no direito e na política - sistemas sociais segmentados territorialmente - ela não se resume de forma alguma ao termo vulgar da corrupção política por interesses particulares. $\mathrm{O}$ núcleo do conceito é o reconhecimento uma corrupção sistêmica generalizada e não meramente pontual, principalmente do sistema jurídico. Trata-se de uma questão estrutural que afeta as expectativas perante este sistema social no âmbito das expectativas sociais e do "agir e vivenciar" (Luhmann, 2007, pp. 258 e ss.). ${ }^{14}$

Portanto, conforme Neves, a seleção jurídica nesses contextos não ocorre de forma autônoma, ou seja, pelo código "lícito/ilícito" (Recht/Unrecht). Outros códigos sociais e interesses bloqueiam essa reprodução. A política e a economia "invadem" ou "superexploram" o direito, que não consegue se reproduzir. Dessa forma, em vez de as comunicações jurídicas operarem por seu código, elas são transpassadas por códigos como "ter/não ter" (propriedade/não propriedade) e "poder/não poder," ou ainda por seleções de redes particularistas, como "amigo/não amigo" ou "patrão/cliente" (relações de patronagem), além de redes de favores.

$\mathrm{O}$ argumento da corrupção sistêmica não deve ser confundido com um elogio do liberalismo ou com um argumento formalista de legalidade, uma vez que a corrupção sistêmica em um "direito alopoiético" (ou que tivesse momentos de alopoiese) obstaria consideravelmente a capacidade de prestação de mecanismos sociais modernos de inclusão de forma generalizada. É por esse motivo que $\mathrm{Ne}$ ves analisa a positividade do direito, a efetividade da Constituição e dos direitos sociais. A análise não recai sobre a sociedade brasileira, mas sobre o reconhecimento de que mecanismos de inclusão social (como cidadania, Estado de bem-estar social, Estado constitucional de direito, direitos sociais, inclusão política etc.) em determinadas regiōes do globo apresentam déficits em relação à sua formulação.

Assim, a análise de Neves, ao caminhar para reconhecer a seletividade da ordem jurídica, redescreve o conceito de constituições nominalistas de Lowenstein (1992, pp. 65 e ss.) e resulta no posterior conceito de constitucionalização simbólica (2007). Desse modo, soma-se à questão da exclusão social outra problemática: quando o direito não é autônomo (nem a política), seus mecanismos de inclusão não se generalizam de forma homogênea e passam a funcionar seletivamente, não ocorrendo a generalização da cidadania. Comentando essa tese de $\mathrm{Ne}$ ves, Jürgen Habermas afirma que, em tais contextos, "a letra imaculada do texto constitucional não é mais do que a fachada simbólica de uma ordem 
jurídica altamente seletiva" (Habermas, 1999, p. 229). Guillermo O'Donnell também se refere aos argumentos de Neves ao abordar a (in)efetividade da lei ((un)rule of law) em alguns países ou "novas poliarquias" da Amérca Latina, quando discorre sobre o desprezo dos privilegiados pelo direito e pela submissão a procedimentos regulares em contextos em que alta violência estatal e de "agentes privados poderosos" pode conviver com "escandalosa impunidade criminal” (O'Donnell, 2000, p. 346).

A base do argumento é a formulação luhmanniana do Estado de bem-estar social como a realização de inclusão política em decorrência do "princípio sociológico da inclusão". O conceito luhmanniano "antigo" de inclusão, desenvolvido em 1981, era definido pela abrangência de toda a população nas performances de sistemas funcionais individuais: isso se relaciona, por um lado, com o acesso aos benefícios de um sistema e, por outro, com a dependência aos modos de vida que determinado sistema impóe. (Luhmann, 1990, p. 34). A marginalização de segmentos populacionais de prestaçôes sistêmicas configuraria o conceito de "exclusão".

Por sua vez, Neves argumenta que em contextos de modernidade periférica - mais extensa em território e população que o chamado centro europeu/norte americano da modernidade - caberia antes reconhecer a dominância de um princípio da exclusão, de modo que não seria possível afirmar que os direitos fundamentais estariam generalizados no âmbito do agir e vivenciar da população nem serviriam como orientação de suas expectativas normativas (Neves, 1992, p. 215). Assim, o autor parte da heterogeneidade estrutural da sociedade mundial e da "marginalização das massas" para discorrer sobre relações de subintegração e sobreintegração ${ }^{15}$ considerando-as típicas de contextos periféricos, principalmente no tocante à generalização da cidadania. Portanto, não seria suficiente apenas a análise dos "marginalizados", pois "a subintegração das massas é inseparável da sobreintegração de grupos privilegiados" (Neves, 1992, p. 95).

Neste contexto, os "marginalizados" são encarados como subcidadãos subintegrados ao sistema jurídico, para quem os direitos fundamentais não têm efetividade e não são concretizados. Para os subintegrados, "os dispositivos constitucionais têm relevância quase exclusivamente em seus efeitos restritivos das liberdades". Eles são integrados ao sistema, "em regra, como devedores, indiciados, denunciados, réus, condenados etc., não como detentores de direitos, credores ou autores" (Neves, 1994, p. 261; 1992, p. 79). O legalismo é imposto de forma dura, principalmente pela atividade repressiva do aparelho estatal. Em termos da teoria da inclusão inicialmente desenvolvida por Luhmann, caberia falar que sua relação com o sistema jurídico é de dependência sem acesso.

Por sua vez, os sobreintegrados constituiriam grupos privilegiados que, muitas vezes com o apoio da burocracia estatal, desenvolveriam açoes bloqueantes da reprodução autônoma do direito, de forma a manter privilégios. Tratar-se-ia de acesso sem dependência, configurando a utilização corrompida de privilégios e ilegalidades, sendo a impunidade sua marca distintiva (Neves, 1992; 1994).

A generalização de relaçôes de subintegração e sobreintegração típica de contextos periféricos em que impera o princípio da exclusão obstaria a configuração da cidadania pensada como princípio de inclusão, tornando-a ineficaz. Seria possível reconhecer o paradoxo do legalismo e da impunidade, operando de forma seletiva. Neves (1992; 1994, p. 256) argumenta que a cidadania, significando conquista da modernidade, pressuporia como condições de sua realização um contexto positivo de juridificação e a autonomia do sistema jurídico.

Com isso, o autor pode formular críticas ao pluralismo jurídico de Santos (Neves, 1992, p. 102; 1995) e àqueles que transporiam de forma acrítica modelos europeus críticos à juridificação e expansão do direito. O problema da modernidade periférica seria menos aquele da invasão direito hipertrofiado em formas autônomas do "mundo da vida", e mais, precisamente, seu oposto: a dificuldade de generalização de um sistema jurídico autônomo (Neves, 1994, p. 268).

Enfim, a crítica formulada por Marcelo Neves deve ser abordada neste artigo na medida em que ela formulou problemas para a teoria da diferenciação funcional luhmanniana e apontou suas limitações "empíricas", demonstrando não apenas que a sociedade moderna é assimétrica, mas também 
que a própria definição de modernidade na teoria luhmanniana fica prejudicada quando olhamos para o contingente de exclusão de amplos setores da sociedade onde os sistemas jurídico e político não parecem funcionar nem de forma autopoiética "pura" nem podem ser explicados como mera superestrutura.

\section{Contextos periféricos na obra tardia de Lubmann}

A guinada de interesse na teoria luhmanniana para questôes vinculadas à integração social e à diferença inclusão/exclusão no reconhecimento de assimetrias na sociedade mundial ocorre pelo reconhecimento de temas que "seriam mais visiveis em contextos de modernidade periférica" (Luhmann, 1995a, grifo meu). Isso levou Luhmann a rever de tal forma alguns pressupostos de sua teoria, adotando a perspectiva do tema inclusão/exclusão, que não deixou de atrair críticas, inclusive daqueles mesmos que iniciaram o debate. ${ }^{16}$

Já em 1993 Luhmann reforça a ideia de uma sociedade mundial, ao discorrer sobre um direito que mantém semelhanças reconheciveis frente a extraordinárias dimensões e diversidade regional de formas de sua violação. Ele argumenta, inclusive, que o "lamento generalizado acerca da exploração pós-colonial dos países da periferia por parte de nações industriais e teorias como a da dependência e da marginalidade constituem antes uma evidência a favor da sociedade mundial - e não contra ela” (Luhmann, 1993, pp. 570-573).

O reconhecimento da assimetria da sociedade mundial nessa obra é manifesto. Luhmann afirma:

A sociedade mundial se caracteriza pelo primado da diferenciação funcional. [...] Contudo, diferenciação funcional não quer dizer, de forma alguma, que haja uma simetria regional de seu desenvolvimento e muito menos uma evolução convergente. [...] Uma sociedade funcionalmente diferenciada é tudo menos uma sociedade harmônica dotada de garantias inerentes de estabilidade. [...] (Idem, pp. 572-573).

É possível supor que o ponto de partida do problema se encontra na inclusão defeituosa de grandes contingentes de população na comunicação dos sistemas funcionais, ou, dito de outra maneira: o problema se encontraria em uma diferenciação aguda entre inclusão e exclusão, produzida sem dúvida pela diferenciação funcional, mas que não apenas é incompatível com ela, mas que também mina sua concretização [sie untergräbt] (Idem, p. 582).

Segundo Luhmann, os sociólogos tendem a abordar este fenômeno como uma estratificação social claramente conformada ou como "uma dominação de classe (sustentada internacionalmente)". Esses conceitos seriam insuficientes, pois remeteriam a ordens de inclusão não mais dominantes, como famílias ou relações de classe fabris do século XIX. Para ele, sob o regime de diferenciação funcional, cada sistema opera seus modos de inclusão e, com a acelerada urbanização e monetarização, "os afetados passam a depender da economia do dinheiro, sem poder, contudo, participar dela" (Idem, pp. 582-583). Com isso, a diferença entre inclusão e exclusão torna-se mais aguda e com efeitos mais amplos. Não se trata de sustentar que sob tais condiçôes direito deixe de existir, mas sim que "[a] descrição desses fenômenos deve ser feita conceitualmente de maneira muito mais diferenciada. Possivelmente, a melhor via de acesso a eles seja obtida com a tese de que a diferença entre inclusão e exclusão serva como uma espécie de metacódigo mediador de todos os demais códigos" (Idem, p. 583).

Então, em referência à obra de Marcelo $\mathrm{Ne}$ ves, Luhmann afirma que, em tais situações, sem dúvida existe um sistema jurídico funcionando pela diferença lícito/ilícito e por seus programas. Entretanto, tal diferença teria pouca relevância tanto para os grupos populacionais excluídos quanto para os grupos incluídos - especialmente os políticos e aqueles que fazem parte da burocracia. Ambos os lados poderiam escolher agir de acordo (ou não) com o direito. $\mathrm{O}$ código jurídico e seus programas funcionariam de modo débil, pois existiriam outras preferências - como a econômica, por exemplo. Isso levaria a generalização no âmbito das expectativas, considerando que, em casos extremos, até a política e a polícia operariam 
sem relevância perante o direito. Ou melhor, saber se o código jurídico será ou não utilizado implicaria antes orientar-se por outra distinção: inclusão/ exclusão (Idem, pp. 583-585). Luhmann defende que essas questôes devem ser trabalhadas com o conceito de integração social, usualmente compreendida em oposição à diferenciação social. Para enfrentar o problema, ele propõe "substituir o tema da integração social pela distinção inclusão/ exclusão" (2007, p. 491).

Luhmann postula a pergunta pela inclusão geral já de forma pessimista. Ou seja, ele vê de forma cética que todos poderiam participar das "vantagens da sociedade". Não se trataria de uma condição passageira ou desenvolvimentista - tal qual proposto pelas teorias da modernização, podemos dizer. Para ele, subsiste o problema de saber se seria possível realizar no âmbito mundial o grau atual de bem-estar de alguns países industrializados, algo que seria improvável "por razōes puramente ecológicas". A isso se somaria a dependência histórica de todos os sistemas autopoiéticos nas especificidades existentes em seus níveis regionais. Sua obra termina de maneira surpreendente:

Diferentemente da teoria parsoniana do sistema geral de ação, vemos a diferenciação funcional como um produto da evolução e não como uma consequência lógica da análise do conceito de ação. Pode muito bem ocorrer que a importância atual do sistema jurídico e o fato de que a sociedade mesma e a maioria de seus sistemas funcionais dependam do funcionamento de um código do direito não seja nada mais que uma anomalia europeia que irá perdendo paulatinamente sua força no curso da evolução da sociedade mundial (1993, pp. 585-586).

Ao levar em conta o problema, Luhmann sustenta ser necessária uma ampliação e uma complementação da teoria da diferenciação social, dominante na sociologia desde os clássicos. Para isso, é necessário levar em conta a covariação diferenciação/integração, voltando-se para a integração social, ainda pouco clara na teoria sociológica. A teoria da diferenciação funcional apresentaria limitações explicativas e seus limites ganhariam relevo nos contextos de países ditos em vias de desenvolvimento ou subdesenvolvidos (1995a, pp. 226-227), ou melhor, partindo de "situações típicas de países localizados na modernidade periférica" para abordar "problemas estruturais da sociedade funcionalmente diferenciada" (Idem, pp. 231-232).

Luhmann define a integração da sociedade como "a limitação dos graus de liberdade que se proporcionam de forma recíproca os sistemas estruturalmente acoplados" (Idem, pp. 227; 1993, p. 584). O autor se afasta, portanto, de "teorias positivas" da integração social que partem de conceitos de integração por valores ou consenso moral (tal como Parsons e Durkheim) - que trabalhariam na lógica desenvolvimentista, visando a uma total inclusão - e aborda a questão da exclusão, tida como sombra lógica do debate sociológico. Luhmann trata-a como uma forma de dois lados, sendo a face interna a inclusão e a externa a exclusão. Portanto, a inclusão (e, analogamente, a exclusão) se refere às pessoas no contexto comunicativo (1995a, pp. 228-229); à relação de pessoas com sistemas sociais.

Para Luhmann, a inclusão na sociedade moderna é regulada internamente pelos diversos sistemas sociais separadamente (Idem, p. 235; 2007, p. 499), não podendo ser coordenada. Nesse contexto, apenas reconhecer "problemas de adaptação de economias locais ao contexto global" não seria suficiente, pois implicaria confiar na capacidade dos sistemas funcionais em se desenvolver e na esperança de sua realização em um caminho único no sentido de uma modernização que se autoimpulsiona. Luhmann critica tal confiança esperançosa como decorrência de teorias da modernização por ele rejeitadas (1995a, pp. 235-236), considerando também problemáticos os "projetos políticos de modernização" (2007, pp. 858 e ss.). Luhmann reconhece que, vistos pela perspectiva dos centros da modernidade, tais contextos periféricos poderiam parecer resultado de uma "modernização fracassada"; entretanto, desenvolve uma "explicação um pouco mais exata" ao reconhecer que a sociedade nesses contextos seria intensamente mais integrada e resultaria em setores de exclusão, o que acarretaria 
a imobilização da política, da economia, do direito, da mobilidade social e até do sistema universitário (1995a, p. 240).

Antes, caberia olhar para os modos de exclusão modernos, evidenciados no contexto periférico em que haveria tamanho abismo entre os âmbitos ou setores de inclusão e exclusão, que essa diferença (inclusão/exclusão) tenderia a assumir a posição de diferenciação primária. ${ }^{17}$ Nesse cenário, grande parte da população ficaria privada das prestações dos sistemas funcionais e são introduzidas "formas imprevistas de estabilização que, aproveitando de forma parasitária as oportunidades oferecidas por estes âmbitos de prestação, criam mecanismos próprios de inclusão e exclusão" e de sua própria manutenção (Idem, p. 235).

Portanto, o conceito de redes de inclusão, operando no plano das interaçôes ou sistemas de contato, se refere a cadeias de reciprocidade - tais como amizades interessadas e relações patrão/cliente - em que os recursos dos subsistemas funcionais são "alienados" para conexões transversais (Idem, p. 236; ver também Gonçalves, 2006, pp. 250-251). Em tais contextos, Luhmann admite uma explicação pela noção de corrupção, mas tende a adotar uma explicação mais voltada à prevalência das redes como "integração transversal" (1995a, pp. 237238), que funcionam competindo com a diferenciação funcional.

Luhmann conclui que a integração da sociedade é frouxa no plano da inclusão, pois os sistemas parciais operam de forma independente ao incluir pessoas a suas prestações. Por exemplo, alguém que tenha um alto nível científico não necessariamente terá boa condição econômica. Contudo, a sociedade se integra de forma muito mais intensa do ponto de vista da exclusão: exclusão gera mais exclusão. Ou seja, existiria uma "espiral de exclusão": um sistema funcional implica a exclusão de outros. Isso se torna algo dramático para Luhmann, que reconhece que os sistemas só têm capacidade de controlar internamente a inclusão e, quanto maior a exclusão de sistemas funcionais, menor a capacidade de inclusão sistêmica em outros (Idem, p. 148; 2007, p. 500).

Nota-se que o conceito de inclusão/exclusão na sociologia de Luhmann não se restringe ao âm- bito jurídico e político de amplas regiōes da sociedade como a América Latina. $\mathrm{O}$ autor aplica o conceito em "nível regional" (2007, p. 639 e ss.) sobre setores de exclusão, inclusive guetos urbanos em grandes cidades de qualquer região do globo. Mesmo reconhecendo que cada âmbito de exclusão tem suas especificidades históricas e empíricas, Luhmann afirma ser possível acessar, por meio de sua teoria da sociedade, suas estruturas comuns ou seu efeito "equifinal" (̈̈quifinal) (1995a, p. 243). Nesses setores, a diferença inclusão/exclusão chegaria a funcionar como um metacódigo, e, neles, as pessoas passariam a contar apenas como meros corpos, separados e aglomerados, em um contexto em que tudo que concebemos como "pessoa" retrocede (Idem, pp. 245 e ss.). No âmbito da exclusão, os meios de comunicação perdem seu sentido específico e imperam a violência física e as necessidades básicas em orientações de satisfação que se orientam por um horizonte de tempo de curto alcance (2007, p. 501).

Luhmann reconhece que contextos tão extremos de exclusão não são a regra e que existe algum grau de inclusão até em setores tidos como excluídos, sendo esse caso-limite o utilizado em sua argumentação (1995a, p. 260). O que cabe ressaltar é a afirmação do autor de que a teoria da diferenciação funcional seria demasiadamente simples para explicar a sociedade, necessitando ser enriquecida com novos deslocamentos teóricos que, em última análise, implicariam abandonar a esperança de que a sociedade possa ser descrita suficientemente bem desde a perspectiva da forma típica predominante de uma diferenciação estratificatória ou funcional (Idem, ibidem).

Em Jenseits von Barberei, Luhmann vai ainda mais longe e afirma que o modo moderno de exclusão é peculiar e que a "estratificação se torna um mero subproduto dos sistemas funcionais, especialmente o econômico e educacional" (1995c, p. 141). Balke (2002, pp. 33 e ss.) compara essa esta observação - em grande parte baseada nada na visita de Luhmann a favelas sul-americanas àquela que Levi-Strauss relata em Tristes trópicos. A fala de Luhmann é direta e questiona frontalmente o postulado da diferenciação funcional da sociedade moderna: 
Para a surpresa dos bem intencionados, devemos reconhecer que a exclusão ainda existe, e existe em uma escala massiva e em tamanhas formas de miséria que elas estão para além da descrição. Qualquer pessoa que ouse visitar as favelas das cidades da América do Sul [...] pode falar sobre isso. [...] Nenhuma pesquisa empírica é necessária. Quem quer que confie em seus olhos pode ver, e ver de forma tão impressionante que todas as explicaçôes disponíveis irão falhar.

Sabemos que há discursos sobre exploração, opressão, marginalidade e sobre uma intensificação na contradição entre centro e periferia. Entretanto, todas essas teorias ainda são governadas pelo desejo da inclusão total e, assim, buscam bodes expiatórios: capitalismo, a aliança dominante entre o capital financeiro e industrial com as forças armadas ou as poderosas famílias de um país. Mas se uma análise mais cuidadosa é feita, não se encontra nada que possa ser explorado ou oprimido. Encontram-se existências reduzidas ao âmbito corporal em sua autodescrição e heterodescrição, tentando apenas sobreviver ao dia seguinte. [...] Se o que é visto é levado em conta, pode-se conceber a ideia do que poderá ser a diferença guia (Leitdifferenz) do próximo século: inclusão e exclusão (1995c, p. 147).

Enfim, Luhmann parece ter levado a sério o desafio e questionado sua teoria da diferenciação funcional, trazendo novos desenvolvimentos e deslocando a discussão dos contextos periféricos para o âmbito da sociedade mundial. Além disso, ele deslocou os debates centrados nos sistemas jurídico e político desses contextos para âmbitos mais abrangentes em sua teoria; trouxe o debate de volta para sua macrossociologia, a qual não encara a sociedade moderna com base em descrição política ou econômica (Luhmann, 2000, pp. 7-12, 116 e ss.). Não é o caso de discutir materialmente o valor de tais teses na teoria luhmanniana, mas de apontar o esforço notável da teoria em compreender e ir além das críticas que lhe foram impostas, demonstrando como o "pensamento sobre a (ou na) periferia" influenciou diretamente mudanças de perspectiva na teoria dos sistemas.

\section{Periferização do centro ou questóes estruturais da sociedade mundial?}

Como vimos, a oposição entre teorias universalistas e contextos periféricos foi essencial para o debate. Nesse sentido, cumpre notar que os conceitos de especificidade, de autenticidade ou de peculiaridade são, sobretudo, conceitos necessariamente relacionais: é impossível não comparar. Sabe-se que comparaçôes podem ser feitas de maneira normativa ou teleológica, considerando um dos lados hierarquicamente superior ao outro. Isso seria equivalente aos pares-oposição por antinomias assimétricas (asymmetrischer Gegenbegriffe, conforme Kosselleck) e ao englobamento do contrário (englobement du contraire, conforme Luis Dumon). ${ }^{18}$ Contudo, essas são oposiçôes formais de conceitos que, mais abstratamente, operam como distinções que resultam "da tentativa de continuar uma arquitetura de mundo hierárquica em face da crescente complexidade social” (Luhmann, 1995c, p. 139): a avaliação positiva de um lado (o lado "melhor" ou "superior") não apenas demarca a oposição, como postula, ao mesmo tempo, uma ordem hierárquica entre essas distinções, em uma dupla função - horizontal e vertical - que, além de distinguir, postula uma relação hierárquica. Niklas Luhmann aborda tais conceitos em sua análise da distinção entre helenos e bárbaros (Idem, ibidem).

Cabe indagar se a busca pela descrição da modernidade periférica em oposição conceitual à modernidade central é necessariamente uma oposição valorativa em qualquer formulação ou, como afirmam os críticos dessa distinção, se seria uma oposição teológica, normativa (Villas Bôas Filho, 2009, esp. pp. 340, 383 e ss.; Domingues, 2011, pp. 28 e ss.), caracterizadora do desvio (Tavolaro, 2011, esp. pp. 91 e ss.) ou proveniente de uma submissão neocolonialista, contra a qual a crítica pós-colonialista apresentaria alternativas (Gonçalves, 2010 esp. pp. 314-315; 2012). Ora, isso nos leva à questão da utilidade de tal distinção (o que ela permite enxergar) e, simultaneamente (como lado externo da mesma forma), sua inutilidade em relação a problemas específicos (seus "pontos cegos"). ${ }^{19}$ Para isso, cumpre notar que Marcelo Neves a concebe como um tipo ideal weberiano, que é uma utopia, 
um "sem lugar". Tipos ideais "nunca são encontrados em forma pura na realidade social, servindo antes como esquemas de sua interpretação com ênfase unilateral em determinados elementos mais relevantes à abordagem" (Neves, 2006, p. 227). Podemos acrescentar a essa caracterização a afirmação de Weber de que, no "que se refere à investigação, o conceito do tipo ideal propóe-se a formar o juízo da atribuição. Não é uma 'hipótese', mas pretende conferir a ela meios expressivos unívocos" (Weber, 2006, p. 72).

A escolha dessa ferramenta heurística, portanto, visou a iluminar questôes abrangentes da sociedade mundial; especificamente, a notar que os mecanismos de inclusão - tais como Estado de bem-estar social, a garantia de direitos fundamentais e a cidadania, todos ligados à segmentação territorial - não se espraiaram de forma homogênica. A noção de modernidade periférica parece ser, portanto, frutífera mais para discussões voltadas à generalização da teoria do que para desenvolver uma "teoria explicativa do direito brasileiro", como vimos nos desenvolvimentos da teoria luhmanniana. Com efeito, um caminho que busque uma "redução da escala de análise" (Villas Bôas Filho, 2009, pp. 375 e ss.) e dê conta de especificidades regionais é possível e necessário. Resta saber até que ponto análises abrangentes e comparativas - como a de Neves - estariam, com isso, enviesadas. Parece-me que tal "redução da escala de análise" pode ser muito útil para a compreensão de contextos regionais; o que necessitaria (como reconhece o próprio Luhmann) de relevante aporte de pesquisa empírica e histórica. Contudo, é importante indagar qual seria a importância de utilizar a teoria luhmanniana para tal projeto, pois reconhecer que ela tem méritos na construção de uma teoria abrangente da sociedade implica notar, ao mesmo tempo, que ela parece ser pouco útil para explicar contextos regionais específicos.

Assim, a distinção centro/periferia da modernidade parece ser construída para possibilitar a tematização desses problemas regionais sem recair em questōes de antropologia cultural (Neves, 2006, pp. 247-248) ou em obstáculos estruturais - como os mencionados ethos ibérico e ethos público - e sem incorrer em interpretações estanques do passado por retirar a pecha de uma região pré-moderna.
Nesse percurso, busca-se desenvolver um conceito que seja compatível com a importância que Luhmann dá à sociedade mundial, evitando-se conceitos como "sociedade brasileira", mas abordando de forma abrangente como sistemas jurídicos e políticos apresentam problemas ao lidar com a questão da inclusão/inclusão em regiōes diversas.

A modernidade periférica aponta para as estruturas comparáveis de um fenômeno pelo qual a autonomia do direito e a efetivação da cidadania podem ser reconhecidas como formas de inclusão em contextos tão diversos como, por exemplo, a América Latina e países africanos. ${ }^{20} \mathrm{O}$ ganho dessa distinção, como Luhmann bem notou, é reconhecer que não se trata de mera marginalização econômica ou da afirmação de que o direito e a política seriam apenas superestruturas do capitalismo. Trata-se de reconhecer um funcionamento prestacional assimétrico de mecanismos de inclusão na sociedade moderna, cuja forma encontrada para combater a exclusão - a cidadania, aqui encarada como uma "conquista evolutiva" (evolutionäre Errungenschaft cf. Luhmann, 2007a, pp. 399 e ss) - se baseou em subsistemas funcionais territorialmente segmentados, como o direito e a política. Pior que isso, nota-se que essa conquista evolutiva parece ter sido muito restrita - "uma anomalia europeia", se quisermos ficar com a formulação provocativa de Luhmann.

Isso aponta para uma questão grave da sociedade mundial contemporânea, que exige novas formulaçōes teóricas, uma vez que nem o conceito de exploração nem a teoria da diferenciação funcional dão conta de explicá-la. Essa é a provocação de Luhmann, presente desde 1992, que parece ir mais longe do que os próprios críticos de sua teoria esperavam.

Para nossa discussão, a questão mais delicada persiste em saber se a distinção centro/periferia da modernidade implicaria necessariamente em um "programa desenvolvimentista" para regiōes periféricas, ainda que decorra "sub-repticiamente" da teoria, que incorreria no erro que ela mesma buscava combater. Não desconhecendo esse risco, bem apontado por Orlando Villas Bôas Filho (2009), é possível interpretar o conceito de outra maneira. Não se trata da busca de implantação de um "programa político para a nação", tal como podemos reconhe- 
cer, grosso modo, no pensamento político brasileiro. Não é o caso de se fazer apologia do centro ou copiar seu percurso institucional em uma espécie de defesa do liberalismo ou do "fim da história", nem apontar soluções políticas para o caso brasileiro ou latino-americano. Se calibrarmos o conceito a partir das posteriores obras luhmannianas, reconhecendo a multiplicidade histórica de contextos regionais, mas abordando apenas suas estruturas comparáveis, o conceito de modernidade periférica parece não incidir em qualquer valorização do centro.

Nota-se, portanto, que a distinção centro/periferia da modernidade parece menos proveitosa para realizar uma "teoria específica da periferia", como Luhmann bem notou em 1992. Este talvez seja um de seus "pontos cegos", como apontaram seus críticos. Sua utilidade é baixa também para explicar setores de exclusão no interior de "Estados democráticos de direito consolidados", como os guetos norte-americanos, tal como Luhmann os descreve. Contudo, essa não parece ter sido a intenção da formulação, voltada para apontar assimetrias na sociedade mundial. Antes, ela me parece mais proveitosa quando vista pela óptica da crítica teórica e do reconhecimento de estruturas comparáveis da sociedade mundial no âmbito dos sistemas jurídico e político.

Assim, reconhecer o "déficit da cidadania" das regiōes periféricas (Neves, 1992; 1994; 2006; e também Villas Bôas Filho, 2009, p. 356) não implicaria uma "sobrevaloração do centro", mas antes apontar para uma estrutura desigual e assimétrica de inclusão na sociedade mundial a partir de seus sistemas territorialmente segmentados.

De qualquer maneira, se o argumento aqui apresentado se sustenta, os desenvolvimentos posteriores realizados pela teoria de Luhmann parecem ter ido além do debate da explicação dos contextos periféricos e se voltado para pensar a exclusão/inclusão em termos mundiais, o que parece ter grande relevância para debates sociológicos atuais.

\section{Considerações finais e reflexões atuais}

O debate sobre a modernidade periférica ocorreu em outro contexto histórico, ${ }^{21}$ e hoje parece ter se deslocado, diante da relevância que ganhou o âmbito global da sociedade. Podemos argumentar, com Brunkhorst (2005, p. 111), que a sociedade mundial funcionalmente diferenciada "surgiu como um projeto europeu, mas hoje ela não mais o é". Assim, não se desconhecem os diversos caminhos históricos e regionais possíveis, como evidenciado pelo conceito de modernidades múltiplas de Eisenstadt (2000), nem se parte de uma análise do "choque de civilizações", mas antes se aponta para um nível de integração inegável da sociedade em escala mundial.

Mesmo que estilizemos um pouco o debate e talvez o enquadremos (ainda) de forma eurocêntrica - o interesse da academia parece indicar uma crise dos Estados de bem-estar social e dos chamados Estados democráticos de direito. Com isso, o interesse se transfere para o combate ao "direito hegemônico", encampado pelas empresas multinacionais, e para a integração de sistemas normativos na sociedade mundial, em discussões pautadas por conceitos como cidadania universal, sistema internacional de direitos humanos, consolidação de uma esfera pública mundial. Esses debates deslocam para a esfera global os debates que antes circundavam os Estados nacionais (Brunkhorst, 2005, p. 114).

A questão em pauta é o reconhecimento de que não haveria sistemas normativos globais para contrapor a globalização econômica (Luhmann, 1993, pp. 582 e ss.; Fischer-Lescano e Teubner, 2004, p. 1000; Neves, 2009) do modo que o Estado de Direito faz regionalmente; esta territorialidade, aliás, tornou a ferramenta analítica da modernidade periférica útil. Poder-se-ia considerar, como Stichweh (2000, pp. 85 e ss.), de maneira mais ampla, um conflito entre a estatalidade de bem-estar e a globalização de sistemas funcionais (Konflikt von Wohlfahrtsstaatlichkeit und Globalisierung der Funktionssysteme).

Marcelo Neves, que se refere a essa questão como uma paradoxal "periferização do centro", duvida dos intentos de regulação da sociedade mundial por uma política transnacional baseada em uma solidariedade cosmopolita. Seu ponto (e sua aposta) se volta para análise do Estado democrático de direito. Nesse sentido, o autor afirma que a "orientação includente do Estado de bem-estar no Ocidente desenvolvido não surgiu isolada da ampla 
exclusão na periferia da sociedade mundial. O problema que se apresenta na atualidade é exatamente a propagação de ondas de exclusão aos países centrais no contexto da globalização econômica" (Neves, 2007, p. 193). Seu diagnóstico é de que a paradoxal periferização do centro na sociedade mundial moderna estaria "relacionada com o desmonte ou superação do clássico welfare state, sem que novos mecanismos de inclusão sejam esboçados clara e seriamente para a construção de uma sociedade de bem-estar fundada nos diversos subsistemas sociais, mesmo apenas nas respectivas regiões do tradicional Estado de bem-estar. O problema redunda na iminente possibilidade de que as formas de exclusão até o presente, típicas dos países periféricos, propaguem-se sobre a modernidade central" (Idem, p. 197). Neves, cético quanto à possibilidade de uma solução global, afirma que saídas poderiam ser antes encontradas no plano regional pelos Estados de direito (Idem, p. 199). Por esse motivo, a aposta de Neves no Estado democrático de direito é mais bem desenvolvida a partir de um modelo de legitimação que enfrente as dificuldades de sua implementação na modernidade periférica e central (ver Neves, 2006, esp. pp. 123 e ss.).

Enfim, a expansão da economia parece não encontrar sistemas normativos internacionais que lhe façam contraponto (ver Habermas, 2009, pp. 120 e ss.; Luhmann, 1993, pp. 582 e ss.; Neves, 2009, pp. 290 e ss.; ainda, de maneira implícita sobre os direitos humanos, Teubner, 2006) em um contexto de crise dos Estados de bem-estar e da capacidade de Estados democráticos de direito de responder a problemas transnacionais, o que tende a propiciar debates sobre a democracia transnacional, sobre a esfera pública mundial e sobre os direitos humanos. As saídas apontadas são, por um lado, a integração transnacional de sistemas normativos e, por outro, a fortificação de Estados de direito para combater territorialmente a exclusão e a expansão do sistema econômico.

Entretanto, se nos voltarmos à análise luhmanniana da exclusão social (e a radicalizarmos consideravelmente para fins de provocação e reflexão), as conclusões a que chegamos parecem mais sombrias. Luhmann lamenta a falta de "certa ironia" aos de- bates democráticos, principalmente das prescriçōes da teoria deliberativa habermasiana de acesso "livre e igualitário" a procedimentos democráticos em discursos orientados ao consenso. Para ele, as pretensões de tornar absolutas a liberdade e a igualdade deixam de enxergar o lado sombrio da exclusão, como se não houvesse "escravidão jurídica, impossibilidade de fala determinada estruturalmente (structurally determined speechlessness) ou efeitos sistêmicos que excluem muitos do trabalho e renda. Tais efeitos da exclusão [...] existem em uma escala massiva e são impossíveis de se desconsiderar" (Luhmann, 1998, pp. 897-899). O autor admite que esforços de teorias da democracia são positivos, mas continua cético com a possibilidade da formação de um sistema global de inclusão política, além de fazer duras críticas ao "discurso intelectual do século XX" que postula que a inclusão na sociedade global deveria ser alcançada por meio da esfera pública (Luhmann, 1995a, p. 233).

Porém, como vimos, a aposta no Estado de bem-estar como forma de inclusão política é entendida tardiamente como limitada e, no limite, como uma "anomalia europeia" cuja generalização enfrenta dificuldades. Apesar disso, o autor não deixa de reconhecer que o Estado de bem-estar (Wohlfahrtsstaat) representa a forma da inclusão da população no sistema político (Luhmann, 2000, pp. 422-423) e, mesmo reconhecendo suas limitações e impossibilidades de generalização no plano mundial - central e periférico (Idem, pp. 426 e ss.) -, Luhmann afirma que seu retrocesso previsível poderia resultar em uma avalanche de exclusão (Idem, p. 428). As políticas da modernização e do desenvolvimento teriam falhado em ver que a "modernização" que almejavam ocorreria de forma seletiva, ou melhor, que se trataria antes de uma questão de análise de estabilização de conquistas evolutivas como "Estado" e "constituição" e de diferenciação de sistemas em contextos determinados (Idem, p.429). Seria mais interessante notarmos atualmente, para além da periferização do centro, que a provocação de Luhmann aponta que não apenas a única forma estrutural de lidarmos com a inclusão de pessoas na política e de combatermos a exclusão (com o Estado social, Sozialstaat) é limitada territorialmente, mas também que ela foi muito restrita em sua genera- 
lização no globo - e está em queda. O problema da exclusão seria tão grave que as tentativas de teorias da democracia deliberativa (de Habermas) de abordá-lo pela referência a "discursos" pareceriam, antes, uma "gozação" (mockery) (Luhmann, 1998, pp. 898-899). Essa problemática leva Luhmann a conjecturar se talvez não estaríamos presenciando o surgimento de um novo sistema social de ajuda social ou ajuda ao desenvolvimento que lidaria com as consequências da exclusão de sistemas sociais (Luhmann, 2007, p. 502). Tal empreitada precisaria de tantos recursos de outros sistemas sociais - política, economia, religião etc. - que talvez tratasse de esforços de sistemas de interação e de organizaçōes em vez de um sistema funcional diferenciado (Idem, ibidem).

Essas consideraçōes devem bastar para demonstrar em que medida o tema "inclusão/exclusão" influenciou significativamente o pensamento tardio de Luhmann. Mais que isso, é possível concluir que Luhmann não poderia ter chegado a conclusões tão contraintuitivas com os desenvolvimentos iniciais de sua teoria sem considerar a condição periférica e sua sociologia.

Por fim, nota-se que esse movimento da teoria sistêmica ocorreu no sentido inverso daquele ao qual estamos acostumados a ver no pensamento social brasileiro e latino-americano: não foi a periferia que utilizou a teoria sistêmica de maneira inadequada - "fora do lugar". Antes, talvez, caiba reconhecer que era a teoria (de Luhmann) que estava fora dos lugares da sociedade mundial.

\section{Notas}

1 Ver Villas Bôas Filho (2009, esp. pp. 195 e ss.). Para uma resposta, ver Schwarz (2012), além de Ricúpero (2008, pp. 64-65 e 68), o qual ressalta o caráter de tensão entre forma e ambiente no pensamento social brasileiro, afirmando haverem "torçôes" necessárias de formas emprestadas pela periferia capitalista.

2 Posteriormente, a problemática teria se espraiado para um "amplo espectro de perspectivas da pesquisa acadêmica" brasileira, implicando, em síntese, um viés "nacionalista metodológico” (Domingues, 2011, pp. 8 e 89).

3 Não cabe neste artigo desenvolver essa tese ou especi- ficar esses movimentos. Nesse sentido, ver Mascareño e Chernilo (2009), Lavalle (2004) e Villas Bôas Filho (2009).

4 Ver Bachur (2010, esp. pp. 33, 259 e ss.), em que há uma interessante análise das noções de "paradoxo" e diferença "sistema/ambiente" na teoria luhmanniana que, em oposição à tradição dialética hegeliana marxista, abandonaria a pretensão de suprassunção (Aufhebung), culminando na proposta crítica de desenvolver uma "dialética da diferenciação funcional" a partir de - e contra? - Luhmann.

5 Tal é a proposta de uma "teoria crítica da (semi)periferia" universalizante e generalizante que não parte de comparações (Domingues, 2011, p. 49).

6 João Paulo Bachur (2010, p. 275) refuta este argumento de maneira clara e precisa, demonstrando porque a teoria luhmanniana não pode ser considerada uma teoria de preferência ao status quo.

7 Sobre essa aproximação, ver Fischer-Lescano (2010); de maneira implícita, Bachur (2010), Ribeiro (2012, pp. 254 e ss.) e Nassehi (2012, p. 404). Markus Schroer (2010, p. 298) chega ao extremo de afirmar que uma possível reconciliação entre as teorias da desigualdade social e da diferenciação funcional teria falhado, mas arremata: "[a]ssim era o que parecia - até a volta de Luhmann do Brasil".

8 Ver Luhmann (1995c), Balke (2002), Nassehi (2012, pp. 404-405). O peso do argumento está na forma argumentativa dos textos de Luhmann e não se apoia em elementos meramente biográficos de sua visita a favelas sul-americanas. Para uma advertência contra generalizações biográficas, ver Luhmann (1987, p. 19).

9 O argumento pareceu ter sido confirmado por Sina Fazin (2012, p. 88), que reconhece que o tema "inclusão/exclusão" na teoria luhmanniana apenas na metade dos anos 1990 passou a colocar em cheque a teoria da diferenciação funcional e gerou discussões.

10 À exceção de Luhmann ([1986] 1989 e [1981] 1990, esp. pp. 34 e ss.) e de outros textos citados por Faryin (2012, p. 88), nos quais a teoria da diferenciação funcional não é mobilizada criticamente.

11 Em todas essas obras, a condição periférica, o exemplo das favelas sul-americanas e/ou o trabalho de Neves são abordados.

12 Ver Luhmann (1997a, esp. "Sobre os fundamentos teórico-sistêmicos da teoria da sociedade"; 2007a, esp. pp. 40 e ss. e 66 e ss.), além do conceito base de autopoiese como sistemas fechados operacionalmente que se reproduzem a partir de seus próprios elementos 
(Maturana e Varela, 1980, p. xvii); por isso, auto (próprio) + poiesis (produção) = autopoiese.

13 Sobre o perigo de se perder no labirinto em interpretações estritas e dogmáticas, ver Bachur (2010, pp. 28-29), além do "labirinto de cristal" de Izuzquiza (2008, pp. 313 e ss.). Para uma análise da teoria luhmanniana como uma "construção chanfrada", ver Villas Bôas Filho (2006, pp. 257-258).

14 Mascareño (2003), diferentemente, afirma que a não generalização do direito ocorreria na América Latina (em seus regimes autoritários de modernização pelo Estado) por meio de indifenciação entre política/direito, por um lado, e economia/política, por outro, em uma "diferenciação funcional concêntrica". Isso obstaria o funcionamento por meios de comunicação simbolicamente generalizados. $\mathrm{O}$ autor fala também em "alopoiese" do direito.

15 Poderíamos também considerar - com base nas formulações posteriores de Luhmann sobre a forma inclusão/exclusão - denominar essas relações como "subinclusão e sobreinclusão". No presente artigo, contudo, manterei o conceito tal como desenvolvido por Neves (1992).

16 Neves (2006, pp. 251-252), reconhece as dificuldades de lidar com o "metacódigo inclusão/exclusão" e manter a noção de diferenciação funcional. Armin Nassehi (2012, p. 404) argumenta que Luhmann não teria desenvolvido o conceito de exclusão de forma a torná-lo operativo, perguntando-se se esse não seria um dos ramos mais fracos de sua teoria. Rodriguez (2010, p. 44) alerta para que não caiamos no ontologismo da explicação pela marginalização, uma vez que os excluídos "não estão desintegrados nem são marginais".

17 Os conceitos de "exclusão primária” e "exclusão secundária", ao se comentar os efeitos que podem adquirir sobre a reprodução do direito, é uma contribuição de Friedrich Müller (1997, pp. 46 e ss.; 2001, pp. 74 e ss.). Ver também Neves (2009, p. 78, nota 61); assumimos que a tese de Neves se aplicaria em contextos jurídicos e constitucionais de "exclusão social primária".

18 Ver a análise de Luhmann (1995c, p. 139) sobre tais conceitos.

19 Essa formulação foi desenvolvida após discussão decorrente de instigantes críticas e comentários de Sérgio Tavolaro na oportunidade da apresentação do primeiro trabalho do $35^{\circ}$ Encontro da Anpocs. Registro aqui meu agradecimento pela contribuição e discussão.

20 Rudolf Stichweh (2005, pp. 45 e ss.) trabalha as implicações de notar que os sistemas funcionais estão globalizados na sociedade mundial, enquanto a exclusão é compreendida em termos regionais com base em condições particulares de funcionamento de sistemas funcionais e acoplamentos estruturais.

21 Poucos anos após a redemocratização de países da América Latina, da queda do muro de Berlin e da dissolução da URSS, os debates se pautavam pelo cenário dos desafios da consolidação democrática (cf. O’Donnel, 1988, esp. pp. 42 e ss.) nos países da chamada terceira onda de democratização, voltando-se para a efetividade de direitos que essas novas democracias prometiam.

\section{BIBLIOGRAFIA}

BACHUR, João Paulo. (2010), Ass portas do labirinto: para uma recepção crítica da teoria social de Niklas Luhmann. Rio de Janeiro, Beco do Azougue.

BALKE, Friedrich. (2002), "Tristes tropiques: systems theory and the literary scene". Soziale Systeme, 8 (folheto 1): 27-37

BOBBIO, Norberto. (2007), Da estrutura à função: novos estudos de teoria do direito. Trad. Daniela Beccaria Versiani. Barueri, SP, Manole.

BRANDĀO, Gildo Marçal. (2005), "Linhagens do pensamento político brasileiro". Dados - Revista de Ciências Sociais, 48 (2): 231-269.

BRUNKHORST, Hauke. (2001), "Globale Solidarität. Inklusionsprobleme der modernen Gesellschaft", in Lutz Wingert e Klaus Günther (orgs.), Die Öffentlichkeit der Vernunft und die Vernunft der Öffentlichkeit. Frankfurt, Suhrkamp.

. (2005), Solidarity: from civic friendship to a global legal community. Trad. do alemão Jeffrey Fynn. Cambridge, MIT Press.

DOMINGUES, José Maurício. (2011), Teoria crítica e (semi)periferia. Belo Horizonte, Editora UFMG.

EISENSTADT, Shmuel. (2000), "Multiple modernities". Daedalus, 129 (1): 1-29.

FARZIN, Sina. (2012), "Inklusion/Exklusion", in Oliver Jahraus, Armin Nassehi et al. (orgs.), Luhmann Handbuch: Leben, Werk, Wirkuntg. Stuttgart, J. B. Metzler. 
FISCHER-LESCANO, Andreas. (2007), "Ex facto ius oritur: procesos de escândalo y el derecho mundial emergente". Doxa-Cadernos de Filosofia del Derecho, 30: 435-450.

(2010), "A teoría crítica dos sistemas da Escola de Frankfurt". Revistas Novos Estudos, 86: 163-177.

FISCHER-LESCANO, Andreas \& TEUBNER, Gunther. (2004), "Regime-collisions: The vain search for legal unity in the fragmentation of global law". Michigan Journal of International Law, 25:999.

GONÇALVES, Guilherme Leite. (2006), "Redes de inclusão" [verbete], in André-Jean Arnaud e Eliane Bothelho Junqueira, Dicionário da Globalização. Rio de Janeiro, Lumen Juris.

. (2010), "Rechtssoziologische Interpretationen des Rechtsdiskurses in Lateinamerika: eine postkoloniale Kritik". Juridikum - Zeitschrift für Kritik, Recht und Gesellschaft, 3: 311-320.

(2012), "El postcolonialismo y la teoria de sistemas: apuentes para una agenda de investigación sobre el derecho en países periféricos", in Marco Estrada Saavedra e René Milán (orgs.), La Teoria de los sistemas de Niklas Luhmann a prueba: horizontes de aplicación en la investigación social en América Latina. Cidade do México, Colegio de México/ Unam.

HABERMAS, Jürgen. (1999), Wahrheit und Rechtfetigung: philosophische Aufsätze. Frankturt, Surhkamp.

(2009), "Hat die Demokratie noch eine epistemische Dimension? Empirische Forschung und normative Theorie", in Jürgen Habermas, Philosophische Texte. Studienausgabe in fünf Bänden. Band 4: Politische Theorie. Frankfurt, Suhrkamp.

IZUZQUIZA, Ignacio. (2008), La sociedad sin hombres. Niklas Lubmann o la teoria como escândalo. 2 ed. Barcelona, Anthropos Editorial.

LAVALLE, Adrian Gurza. (2004), Vida pública $e$ identidade nacional: leituras brasileiras. São Paulo, Globo.

LUHMANN, Niklas. (1975), "Die Weltgesellschaft”, Soziologische Aufklärung 2: Aufsätze zur theorie der Gesellschaft. 6 ed. Wiesbaden, Hessen, Springer.

(1980), Gesellschaftsstruktur und Semantik: Studien zur Wissenssoziologie der modernen Gesellschaft. Frankfurt, Suhrkamp, vol. 1

. (1981), "Wie ist soziale Ordnung möglich?", Gesellschaftsstruktur und Semantik: Studien zur Wissenssoziologie der modernen Gesellschaft. Frankfurt, Suhrkamp, vol. 2.

. (1983 [1972]), Sociologia do direito I.

Trad. Gustavo Bayer. Rio de Janeiro, Tempo Brasiliense.

(1987), Archimedes und wir - Inter-

views. Berlim, Merve.

([1986] 1989), Ecological communication. Trad. do alemão John Bednarz Jr. Chicago, University of Chicago Press.

. ([1981] 1990), Political theory in the welfare state. Trad. do alemão John Bednarz Jr. Berlim/Nova York, Walter de Gruyter.

(1992), "Zur Einführung”, in Marcelo Neves, Verfassung und Positivität des Rechts in der peripheren Moderne: Eine theoretische Betrachtung und eine Interpretation des Falls Brasilien. Berlim, Duncker und Humblot. (1993), Das Recht der Gesellschaft. Frankfurt, Suhrkamp. (1995a), "Inklusion und Exklusion", Soziologische Aufklärung 6: Die Soziologie ind der Mensch. 3 ed.Opladen, Leverkusen, Westdeutscher.

([1984] 1995b), Social systems. Trad. do alemão John Bednarz Jr. Stanford, Stanford University Press.

. (1995c), "Jenseits von Barbarei", Gesellschaftsstruktur und Semantik. Studien zur Wissenssoziologie der modernen Gesellschaft. Frankfurt, Suhrkamp, vol. 4.

(1996), Introducción a la teoria de sistemas. Cidade do México, Universidad Iberoamericana.

(1997a), "Sobre os fundamentos teórico-sistêmicos da teoria da sociedade", in Clarissa Eckert Baeta Neves e Eva Machado Barbosa Samkios (orgs.), A nova teoria dos sistemas. Porto Alegre, Editora da UFRGS/Goethe-Institut/ICBA. 
(1997b), "Globalization or world society: how to conceive of modern society?". International Review of Sociology, 7 (1): 67-79. [Disponível em português in Cícero Araújo e Leopoldo Waizbort, "Sistema e Evolução na Teoria de Luhmann" (mais - Um texto de Niklas Luhmann: 'A Sociedade Mundial como Sistema Social')". Lua Nova, 47: 179-200.]

(1998), "Quod omnes tangit. Remarks on Jürgen Habermas's legal theory”, in Michel Rosenfeld e Andrew Arato (eds.), Habermas on law and Democracy: critical Exchanges. Berkeley, University of California Press.

. (2000), Die Politik der Gesellschaft. Frankfurt, Suhrkamp.

. (2005), Einführung in die Theorie der

Gesellschaft. Heidelberg, Carl-Auer.

. ([1997] 2007), La sociedad de la so-

ciedad. Trad. alemão Javier Torres Nafarrate e Dario Rodrígues Mansilla. Cidade do México, Editorial Herder/Universidad Iberoamericana/ Deutscher Akademischer Austausch Dienst.

MATURANA, Humberto \& VARELA, Francisco. (1980), Autopoiesis and cognition: the realization of the living. Dordrecht/Boston/Londres, D. Reidel Publishing Company. (Boston Studies in the Philosophy of Science, vol. 42.)

MASCAREÑO, Aldo. (2003), Teoría de sistemas de América Latina. Conceptos fundamentales para la descripción de una diferenciación funcional concéntrica. Persona y Sociedad, XVII (2): 9-26. Disponível em: http://www.personaysociedad. $\mathrm{cl} /$ teoria-de-sistemas-de-america-latina-conceptos-fundamentales-para-la-descripcion-de-una-diferenciacion-funcional-concentrica/. Acesso em: 3 maio 2012.

MASCAREÑO, Aldo \& CHERNILO, Daniel. (2009), "Obstacles and Perspectives of Latin American Sociology: Normative Universalism and Functional Differentiation", Soziale Systeme, 15 (1): 72-96.

MÜLLER, Friedrich. (1997), Wer ist das Volk? Die Grundfrage der Demokratie - Elemente einer Verfassungstheorie VI. Berlim, Duncker und Humblot. (Schriften zur Rechtstheorie, vol. 197.)

. (2001), Demokratie in der Defensive: funktionelle Abnutzung - soziale Exklusion Globalisierung. Berlim, Duncker und Humblot (Elemente einer Verfassungstheorie VII - Schriften zur Rechtstheorie; Heft 197)

NASSEHI, Armin. (2012), "Rezepzion: Soziologie" in Oliver Jahraus, Armin Nassehi et al. (orgs.), Luhmann Handbuch: Leben, Werk, Wirkuntg, Stuttgart, J. B. Metzler.

NEVES, Marcelo. (1992), Verfassung und Positivität des Rechts in der peripheren Moderne: Eine theoretische Betrachtung und eine Interpretation des Falls Brasilien. Berlim: Duncker und Humblot.

. (1994), "Entre subintegraçãoo e sobreintegração: a cidadania inexistente". Dados - Revista de Ciências Sociais, 37 (2): 253-276.

. (1995), "Do pluralismo jurídico à miscelânea social: o problema da falta de identidade $\mathrm{da}(\mathrm{s})$ esferas de juridicidade na modernidade periférica e suas implicações na América Latina". Direito e Debate, ano V, 15: 7-37. 1995 Política, São Paulo, v. 37, 1996 (pp. 93-106) (2004), "E se faltar o décimo segundo camelo? Do direito expropriador ao direito invadido", in André-Jean Arnaud e Dalmir Lopes Jr. (orgs.), Niklas Luhmann: do sistema social à sociologia jurídica, Rio de Janeiro, Lumen Juris. . (2006), Entre Têmis e Leviatã: uma relação difícil. O estado democrático de direito a partir e além de Luhmann e Habermas. [tradução do autor] São Paulo, Martins Fontes.

. (2007), A constitucionalização simbólica. São Paulo, Martins Fontes. . (2009), Transconstitucionalismo. São Paulo, WMF Martins Fontes.

O’DONNELL, Guilhermo. (1988), A democracia no Brasil: dilemas e perspectivas. São Paulo, Vértice. . (2000), "Poliarquias e a (in)efetividade da lei na América Latina: uma conclusão parcial”. Trad. Otacilio Nunes, in Juan E. Mendes, Guilhermo O’Donnell e Paulo Sérgio Pinheiro, Democracia, violência e injustiça: o não-estado de direito na América Latina, São Paulo, Paz e Terra.

RIBEIRO, Pedro Henrique. (2012), "Entre eclusas e espelhos: a esfera pública vista a partir de uma leitura crítica de Niklas Luhmann e de 
debates contemporâneos". Dissertação de mestrado. São Paulo, FD-USP.

RODRIGUEZ, Darío M. (2010), "Los limites del estado em la sociedad mundial: de la política al derecho", in Marcelo Neves, Transconstitucionalidade do direito: novas perspectivas dos conflitos entre ordens jurídicas, São Paulo, Quartier Latin/Daad.

RICUPERO, Bernardo. (2008), "Da formação à forma. Ainda as “idéias fora do lugar". Lua Nova, 73: 59-69.

SCHROER, Markus. (2010) "Funktionale Differenzierung versus soziale Ungleichheit", in Georg Kneer e Stephan Moebius (orgs.), Soziologische Kontroversen: Beiträge zu einer anderen Geschichte der Wissenschaft vom Sozialem, Frankfurt, Suhrkamp.

SCHWARZ, Roberto. (2005), "As idéias fora do lugar", in Roberto Schwarz, Ao vencedor as batatas, 5 ed., São Paulo, Editora 34.

. (2012), "Por que ideias fora do lugar?", Martinha versus Lucrécia: ensaios e entrevistas. São Paulo, Companhia das Letras.

STICHWEH, Rudolf. (2000), Die Weltgesellschaft. Soziologische Analysen. Frankfurt, Suhrkamp. . (2004), "Strangers in world society indifference and minimal sympathy", in Stefan Iglhaut e Thomas Spring (eds.), Science + Fiction: between nanoworlds and global culture, Berlim, Jovis. [Citado conforme cópia mimiografada disponível em: http://www.uni-bielefeld.de/(de)/soz/iw/pdf/stichweh_9/. Acesso em 5 jun. 2012.]

. (2005), Inklusion und Exklusion: Studien zur Gesellschaftstheorie. Bielefeld, Transcript.

TAVOLARO, Sérgio Barreira de Faria. (2011), Cidadania e modernidade no Brasil (1930-1945): uma crítica a um discurso hegemônico. São Paulo, Annablume.

TEUBNER,Gunther. (2006), "Die anonyme Matrix: Zu Menschenrechtsverletzungen durch 'private' transnationale Akteure". Der Staat: Zeitschrift für Staatslehre und Verfassungsgeschichte, deutsches und europäisches öffentliches, 44:161-187.

VILLAS BÔAS FILHO, Orlando. (2006), $O$ di- reito na teoria dos sistemas de Niklas Luhmann. São Paulo, Ed. Max Lominad. . (2009), Teoria dos sistemas e o direito brasileiro. São Paulo, Saraiva.

WEBER, Max. (2006), A "objetividade" do conhecimento em ciências sociais. Trad. comentada Gabriel Cohn. São Paulo, Ática. 


\section{LUHMANN "FORA DO LUGAR”? COMO A “CONDIÇÃO PERIFÉRICA” DA AMÉRICA LATINA IMPULSIONOU DESLOCAMENTOS NA TEORIA DOS SISTEMAS}

\section{Pedro Henrique Ribeiro}

Palavras-chave: Teoria dos sistemas; Niklas Luhmann; Pensamento social brasileiro; Modernidade periférica.

$\mathrm{O}$ artigo objetiva demonstrar uma guinada teórica na sociologia de Niklas Luhmann (após 1992) decorrente da necessidade de lidar com contextos sociais periféricos da modernidade. Argumenta-se ter ocorrido: a revisão da teoria da diferenciação funcional como faceta caracterizadora da modernidade; um deslocamento de interesse para temas de integração social (ou inclusão/ exclusão); e um refinamento do conceito de sociedade mundial (não harmônica). Utiliza-se o conceito de "modernidade periférica” e algumas críticas por ele recebidas para abordar descrições da sociedade mundial moderna e são apresentados debates atuais no campo. Sustenta-se que a tensão (paradoxal) entre teorias "estrangeiras" universalistas e casos de exceção é proveitosa para o desenvolvimento do debate sociológico. Busca-se deslocar o usual foco da explicação de contextos sociais "exóticos" para os desenvolvimentos da teoria em si e das análises sobre a sociedade mundial moderna.

\section{LUHMANN “OUT OF PLACE”? HOW THE "PERIPHERAL CONDITION” OF LATIN AMERICA PROMPTED DISPLACEMENTS IN THE SYSTEMS THEORY}

\section{Pedro Henrique Ribeiro}

Keywords: Systems theory; Niklas Luhmann; Brazilian social thought; Peripheral modernity.

The article aims to (I) show a theoretical turn in Niklas Luhmann's sociology (after 1992) that followed its need to face "peripheral social contexts" of modernity. The argument states [that] (a) a revision of functional differentiation theory as the main characterizing feature of modernity, (b) a shift of interest towards themes of social integration (inclusion/ exclusion) and (c) a sophistication of the (non-harmonic) world society took place in this theoretical turn. (II) The "peripheral modernity" concept and the critics to it are applied to approach descriptions of contemporary world society (III) and some recent debates on the field. It is argued that the (paradoxical) tension between "'foreign' universalistic theories" and "exception cases" is a fruitful one to the further development of sociological debate. It is intended to promote a shift from the usual focus on the "explanation on 'exotic' social contexts" towards [intern] inner theoretical developments and further analysis on the modern world society.

\section{LUHMANN “DÉPLACÉ”? DE QUELLE FAÇON LA "CONDITION PÉRIPHÉRIQUE” DE L'AMÉRIQUE LATINE A IMPULSIONÉ DES DÉPLACEMENTS DANS LA THÉORIE DES SYSTĖMES}

Pedro Henrique Ribeiro

Mots-clés: Théorie des systèmes; Niklas Luhmann; Pensée sociale brésilienne; Modernité périphérique.

L'article a pour objectif de démontrer un tournant théorique dans la sociologie de Niklas Luhmann (après 1992) découlant du besoin de travailler avec des contextes sociaux périphériques de la modernité. Nous argumentons qu'il y a eu une révision de la théorie de la différenciation fonctionnelle en tant que facette caractéristique de la modernité ainsi qu'un déplacement d'intérêt vers des thèmes de l'intégration sociale (ou d'inclusion/d'exclusion), et un raffinement du concept de société mondiale (non harmonique). Nous avons employé le concept de "modernité périphérique " et quelques critiques qu'il a reçu pour avoir abordé des descriptions de la société mondiale moderne. Nous présentons également de débats actuels dans ce domaine. Nous défendons que la tension (paradoxale) entre les théories " étrangères " universalistes et des cas d'exception est utile pour le développement $\mathrm{du}$ débat sociologique. Nous essayons de déplacer le point de vue habituel de l'explication des contextes sociaux " exotiques " vers les développements de la théorie en elle-même et des analyses sur la société mondiale moderne. 